\title{
Heating, Ventilating, and Air-Conditioning: Recent Advances in Diagnostics and Controls to Improve Air-Handling System Performance
}

\author{
C.P. Wray ${ }^{a}$, M.H. Sherman ${ }^{a}$, I.S. Walker ${ }^{a}$, D.J. Dickerhoff ${ }^{a}$ \\ and C.C. Federspiel ${ }^{\mathrm{b}}$ \\ ${ }^{a}$ Lawrence Berkeley National Laboratory \\ 1 Cyclotron Road MS 90R3074, Berkeley, California 94720 \\ ${ }^{b}$ Federspiel Controls \\ 701 El Cerrito Plaza, El Cerrito, California 94530
}

\begin{abstract}
The performance of air-handling systems in buildings needs to be improved. Many of the deficiencies result from myths and lore and a lack of understanding about the non-linear physical principles embedded in the associated technologies. By incorporating these principles, a few important efforts related to diagnostics and controls have already begun to solve some of the problems. This paper illustrates three novel solutions: one rapidly assesses duct leakage, the second configures ad hoc duct-static-pressure reset strategies, and the third identifies useful intermittent ventilation strategies. By highlighting these efforts, this paper seeks to stimulate new research and technology developments that could further improve air-handling systems.
\end{abstract}

\section{INTRODUCTION}

Although the energy efficiency of many heating, ventilating, and air-conditioning (HVAC) system components in buildings has substantially improved over the past 30 years (e.g., furnaces, chillers, air-handler drives), there is still a need to make other equally critical components more efficient (e.g., the air-distribution system, which delivers heating, cooling, and ventilation air to occupied spaces).

There are multiple problems that lead to poorly-performing air-handling systems. Examples include poor installation quality (e.g., duct joints are poorly sealed, especially downstream of terminal boxes and in exhaust systems); inadequate controls (e.g., unnecessarily closed terminal box dampers restrict flow and result in large pressure differences across the fan); unnecessarily restrictive codes and standards (e.g., requiring constant mechanical ventilation airflows, which can actually reduce indoor air quality in cases such as during periods of high outdoor ozone concentrations); and the lack of reliable diagnostic tools and procedures for system commissioning (e.g., industry-standard duct leakage test procedures cannot be used for ducts downstream of terminal boxes).

Together, myths and lore about system performance and a lack of understanding about the non-linear physical principles embedded in air-handling system technologies contribute to many of these problems. For example, a common myth is that air leaking from variable-air-volume (VAV) supply ducts located in the ceiling return plenums of 
a large commercial building does not matter, because the ducts are inside the building. In fact, however, the ducts are outside the conditioned space, the leakage short-circuits the air distribution system, supply fan airflow increases to compensate for the undelivered thermal energy, and fan power increases considerably.

By incorporating the physical principles that govern air-handling system performance, a few important efforts related to diagnostics and controls have already begun to solve some of these problems. They provide a solid foundation for further improvements to air-handling system performance in new and existing buildings. Three examples are:

1. A simple technique for rapidly measuring duct leakage in houses ${ }^{1,2}$. Most existing test methods use duct pressurization to precisely measure the aggregated size of leaks (but not the flow through them at operating conditions). Because duct system pressures are not uniform and knowing the location and size of hundreds of individual leaks is practically impossible, there are large uncertainties associated with this measurement technique. The new test method, called DeltaQ, instead measures the change in flow through duct leaks as the pressure across them is changed. The pressure difference changes are created by pressurizing and depressurizing the whole house (including the ducts) using a blower door. This new method provides duct leakage estimates during system operation and uses equipment and techniques already familiar to building technicians.

2. A new, widely-applicable diagnostic-based duct-static-pressure control strategy for VAV systems ${ }^{3,4}$. A correlation between duct pressure and flow is determined from data obtained by measuring these parameters at multiple duct pressures over the fan's operating range, while the terminal box dampers attempt to control flow in response to an approximately constant thermostat setpoint. The goal is to define the regions where all terminal boxes are in control (dampers modulating) and where the boxes are starved (one or more dampers are wide open). The control region correlation can be implemented within an existing direct-digital-control (DDC) system or, when pneumatic controls are present, in a control system overlay. The system can then operate with the terminal box dampers as wide open as possible while still maintaining thermal control.

3. A new dimensionless model of ventilation efficacy ${ }^{5}$. This model allows one to assess whether an intermittent ventilation strategy will provide the same or better indoor air quality compared to the common continuous strategy specified by codes and standards. In particular, using the model, one can determine which intermittent ventilation strategies are effective for ventilationrelated load-shifting and for providing temporary protection against poor outdoor air quality.

By providing highlights of these three efforts, with a particular emphasis on the non-linear physical principles embedded in these technological solutions, this paper seeks to stimulate new research and technology developments that could further improve air-handling system performance. 


\section{DELTAQ DUCT LEAKAGE TEST}

Field tests in thousands of houses, several hundred small commercial buildings, and a few dozen large commercial buildings suggest that duct leakage is widespread and large. It is often 25 to $35 \%$ of system airflow in small commercial buildings, and can be as large as 10 to $25 \%$ in houses and large commercial buildings. Consequently, assessing duct leakage is a key factor in determining energy losses from forced air heating and cooling systems. Specifically, for energy calculations, it is the duct leakage airflow to outside of the conditioned space at operating conditions that is required. Using the common industry method of duct pressurization and assuming pressures at leaks is not a reliable indicator of determining whole-system leakage flow; instead, leakage flows themselves need to be measured ${ }^{6}$.

Just like a building envelope leakage test, the DeltaQ test measures the pressure difference across the envelope while simultaneously measuring the airflow through the blower that is used to change the envelope pressure difference. In the DeltaQ test, pressurization and depressurization tests are performed twice: once with the air handler off and again with the air handler on. This procedure is used because the magnitudes (and for some leaks, the direction) of duct leak airflows are different when the air-handler is off or on. At each envelope pressure difference $(\Delta P)$ in the airhandler off and on tests, there are a pair of blower door flow data; the difference between each pair gives the DeltaQ $(\Delta Q)$.

Figure 1 shows an example pair of test points for a pressurization test. Return and supply ducts located outside the building envelope connect the air-handler to the conditioned space. The red (upper) text denotes the flows and pressures in the airhandler off condition; the green (lower) text denotes the air-handler on condition. In this case, $\Delta \mathrm{Q}$ is $-80 \mathrm{cfm}$.

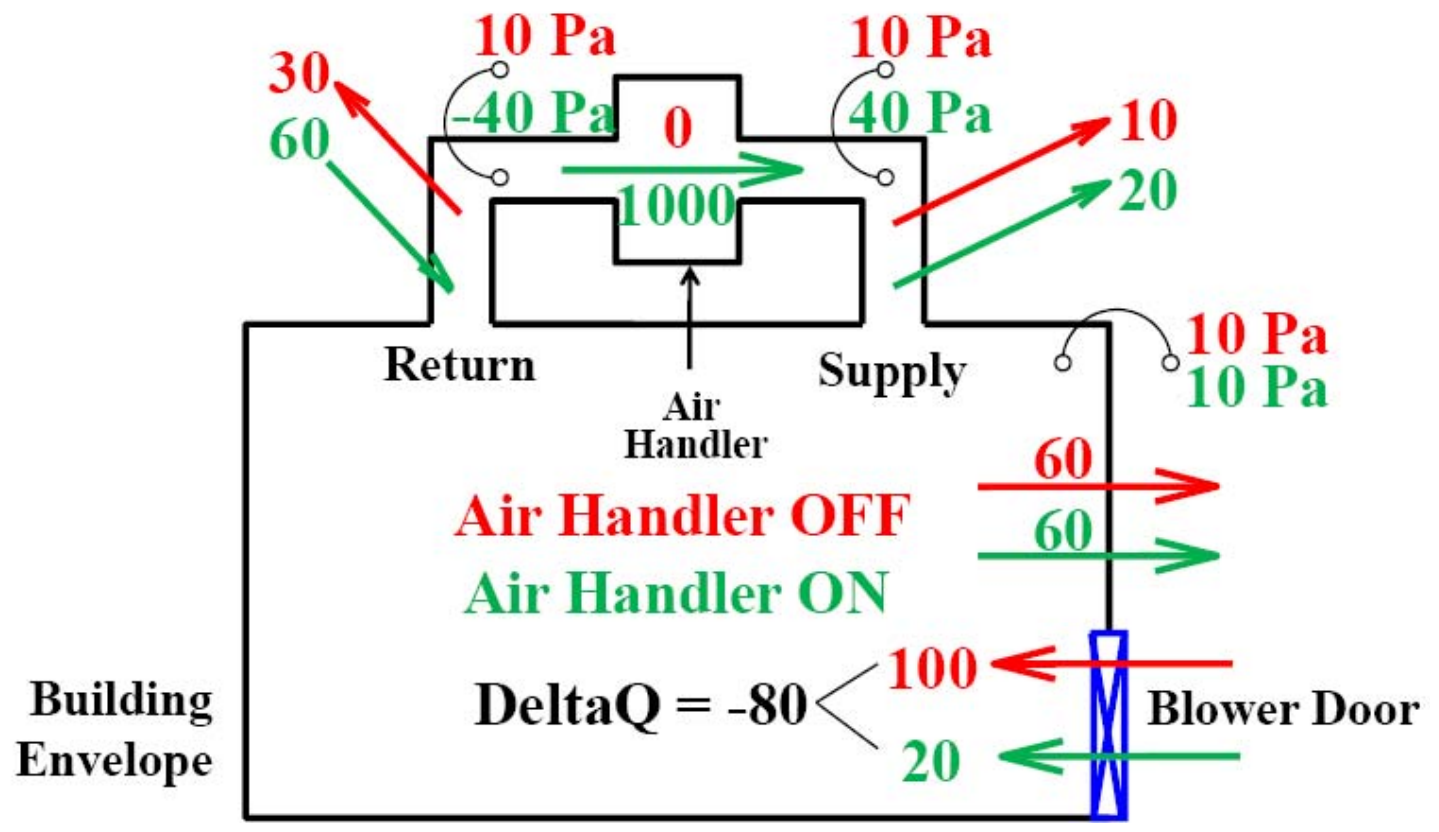

FIGURE 1. Example of DeltaQ Airflows and Pressures with Air-Handler Off and then On 
Figure 2 shows a set of blower door flows together with the corresponding envelope pressures for a series of pressurization and depressurization tests. The data for each of the four parts of the test were acquired using a "ramping" technique ${ }^{2}$, which uses the blower door to gradually increase the envelope pressure difference from zero to a peak value over a period of about 90 seconds and then gradually decrease the pressure difference back to zero over the following 90 seconds.

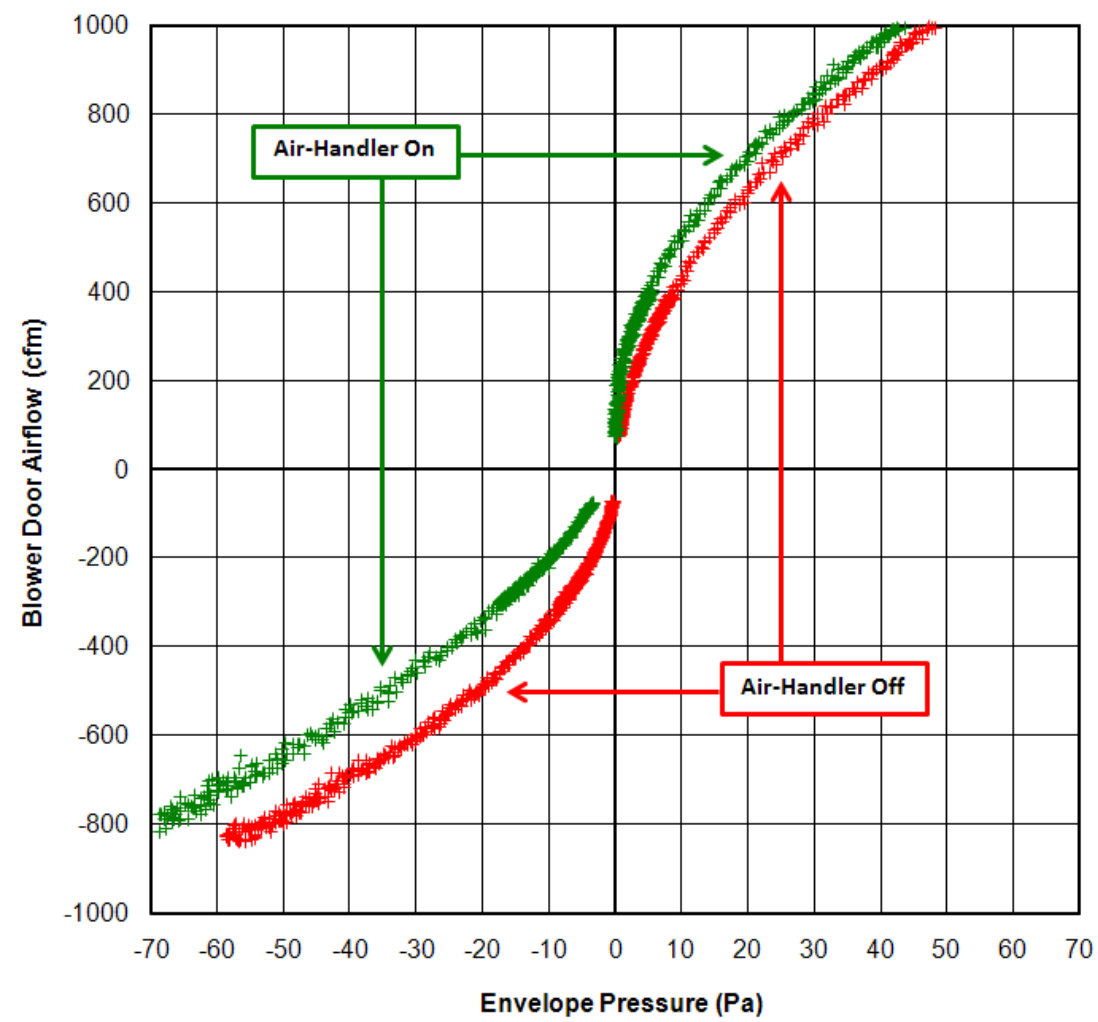

FIGURE 2. Example of DeltaQ Airflow and Pressure Test Data

Converting the test data to duct leakage flows requires the use of the flow-balancebased DeltaQ model ${ }^{1,7,8}$ (Eq. 1) and the use of regression routines to determine the model parameters that best fit the measured data $(\Delta Q$ and $\Delta P)$.

$$
\Delta Q(\Delta P)=Q_{s}\left[\left(1+\frac{\Delta P}{\Delta P_{s}}\right)^{n_{s}}-\left(\frac{\Delta P}{\Delta P_{s}}\right)^{n_{s}}\right]-Q_{r}\left[\left(1-\frac{\Delta P}{\Delta P_{r}}\right)^{n_{r}}+\left(\frac{\Delta P}{\Delta P_{r}}\right)^{n_{r}}\right]
$$

In particular, the unknowns in Eq. 1 are:

$Q_{s}=$ the supply duct leakage flow,

$Q_{r}=$ the return duct leakage flow,

$\Delta P_{s}=$ the characteristic pressure difference between the supply duct and house,

$\Delta P_{r}=$ the characteristic pressure difference between the return duct and house,

$n_{s}=$ the supply duct leakage pressure exponent, and

$n_{r}=$ the return duct leakage pressure exponent.

The characteristic pressures, $\Delta P_{s}$ and $\Delta P_{r}$, sometimes can be measured, typically at the air-handler plenums or some fraction thereof, but in most situations the pressure at 
the leak site is unknown and it is advantageous to let these pressures be determined by best fits to the $\Delta Q$ and $\Delta P$ measurements. Analysis of many DeltaQ tests has shown that fitting to the measured data is more robust if the duct leakage pressure exponents are fixed ${ }^{9,10}$. In particular, experiments to characterize the pressure exponents for a wide range of duct configurations have shown that a value of 0.6 is suitable for most duct systems. However, if it is known that most of the leakage is orifice-like or is a disconnected duct, then a pressure exponent of 0.5 is preferred.

Because many data pairs are analyzed for the ramping technique, Walker and Dickerhoff $^{2}$ have found that standard least squares routines can take significant time to achieve a solution (several hours in some cases). To reduce the time requirements, they developed a new "pressure scanning" technique that takes 10 seconds or less. This technique applies Eq. 1 to fixed characteristic supply and return pressure combinations. For each supply and return pressure pair, the least squares error is calculated by comparing the estimated $\Delta \mathrm{Q}$ to the measured $\Delta \mathrm{Q}$. The supply and return pressure combination that generates the smallest error is the solution to the DeltaQ equation, together with their corresponding leakage airflows.

Figure 3 shows $\Delta Q$ as a function of the envelope pressures. This figure also shows the calculated the fitted $\Delta Q$ curve based on Eq. 1. In this case, the $\Delta Q$ curve fits the data well and the corresponding leakage estimate is $130 \mathrm{cfm}$ for the supply ducts and $17 \mathrm{cfm}$ for the return ducts. For a system that has a $1000 \mathrm{cfm}$ flow through the airhandler, these results indicate that the supply ducts are leaky (13\% leakage) and need to be sealed; in contrast, the return ducts are tight (about $2 \%$ leakage).

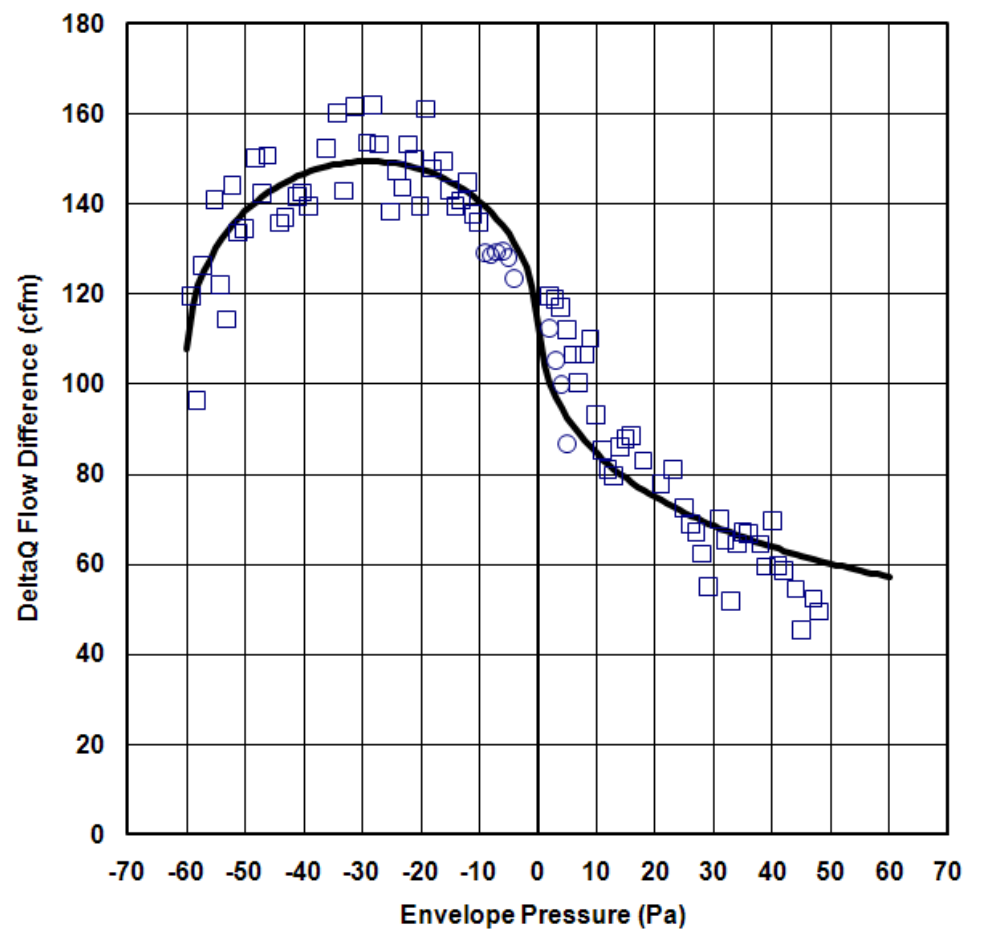

FIGURE 3. Example of Calculated DeltaQ Data and Fitted DeltaQ Line

Field tests have shown that the DeltaQ repeatability depends on both the envelope leakage and weather conditions. In general, a leakier building envelope and windier 
weather can lead to greater uncertainty. For these tests, the building envelope seems to dominate and a reasonable rule of thumb is that the repeatability is about $1 \%$ of the envelope airflow at $50 \mathrm{~Pa}$. Future efforts should focus on field testing this diagnostic in more houses to confirm these preliminary findings, and to extend its applicability to small commercial buildings, which are similar in many respects to houses.

\section{DUCT STATIC PRESSURE DIAGNOSIS AND CONTROL}

VAV air-handling systems regulate the flow through the fan to maintain a fixed static pressure in the main supply duct. This strategy ensures that terminal boxes have enough pressure to operate properly, but it is inefficient because the duct static pressure will be higher than necessary most of the time. Considerable energy savings can be achieved if the duct pressure is reduced at part load. For example, Lorenzetti and Norford ${ }^{11}$ showed that fan energy consumption in VAV systems could be reduced by 19 to $42 \%$ with static pressure reset (SPR). Federspiel ${ }^{3}$ found that reducing the pressure in response to reduced supply airflow could reduce fan power consumption by $26 \%$ and cooling power by $17 \%$.

The SPR concept is not new, but it is still not widely used for several reasons:

1. SPR traditionally has required a networked DDC system with digital controls at terminal boxes, and is susceptible to box control failures. Even today, many systems have pneumatic controls rather than digital controls.

2. Some SPR strategies require terminal box damper position sensors. It is not common, however, for terminal boxes to have these sensors. When present, these sensors may be insufficiently accurate to support an SPR strategy.

3. SPR adds control complexity. DDC systems may not have sufficient bandwidth and programming capabilities to support the additional demands of SPR.

4. Many SPR strategies adjust (reset) the static pressure using a feedback loop that regulates the most-open terminal damper to a nearly open position (e.g., 90\% open). SPR strategies that use feedback are difficult to tune.

Engineers have overcome these problems by inventing ad hoc SPR strategies that reset static pressure based on some measurable quantity that is related to the load (e.g., flow, outdoor temperature, time, or a combination of these). Ad hoc reset strategies have the advantage of not requiring digital terminal controls, can be implemented through control overlays, and cannot destabilize the static pressure loop because they do not involve feedback. However, they must still be configured (typically carried out through an iterative trial and error process).

Federspiel $^{3,4}$ has recently developed a diagnostic-based method to configure ad hoc SPR strategies so that they can achieve improved performance. The method involves defining two modes of operation. When the duct static pressure is high enough that all of the terminal boxes are meeting the load, the system is operating in the controlled mode. When one or more terminal box dampers are $100 \%$ open and not meeting the load, the system is in the starved mode. The following 2 to 4 hour long test procedure is used to collect data while the system is forced to operate in both modes with fixed thermostat settings:

1.1. Start at a sufficiently high pressure (e.g., the system design pressure) and wait for the terminal box dampers to reach equilibrium (e.g., 15 minutes). Record the 
flow through the supply fan and the duct static pressure. The velocity pressure near the fan inlet can be used as a surrogate for the flow through the supply fan.

1.2. Reduce the duct static pressure by a small amount (e.g., $25 \mathrm{~Pa}$ ), wait for the dampers to reach equilibrium again, and then record the time, supply flow, and static pressure. Repeat Step 2 until the supply flow is less than a pre-determined limit (e.g., $70 \%$ of the starting flow).

1.3. Increase the pressure by a small amount (e.g., $25 \mathrm{~Pa}$ ), wait for the dampers to reach equilibrium again, and then record the time, supply flow, and static pressure. Repeat Step 3 until the pressure equals the starting pressure.

An example dataset is shown in Figure 4. The lowest supply duct pressure that keeps all the terminal boxes in control is the critical pressure. This pressure is at the intersection of the controlled and starved data. A dual-mode analytical model can be applied to the test data to determine the critical pressure.

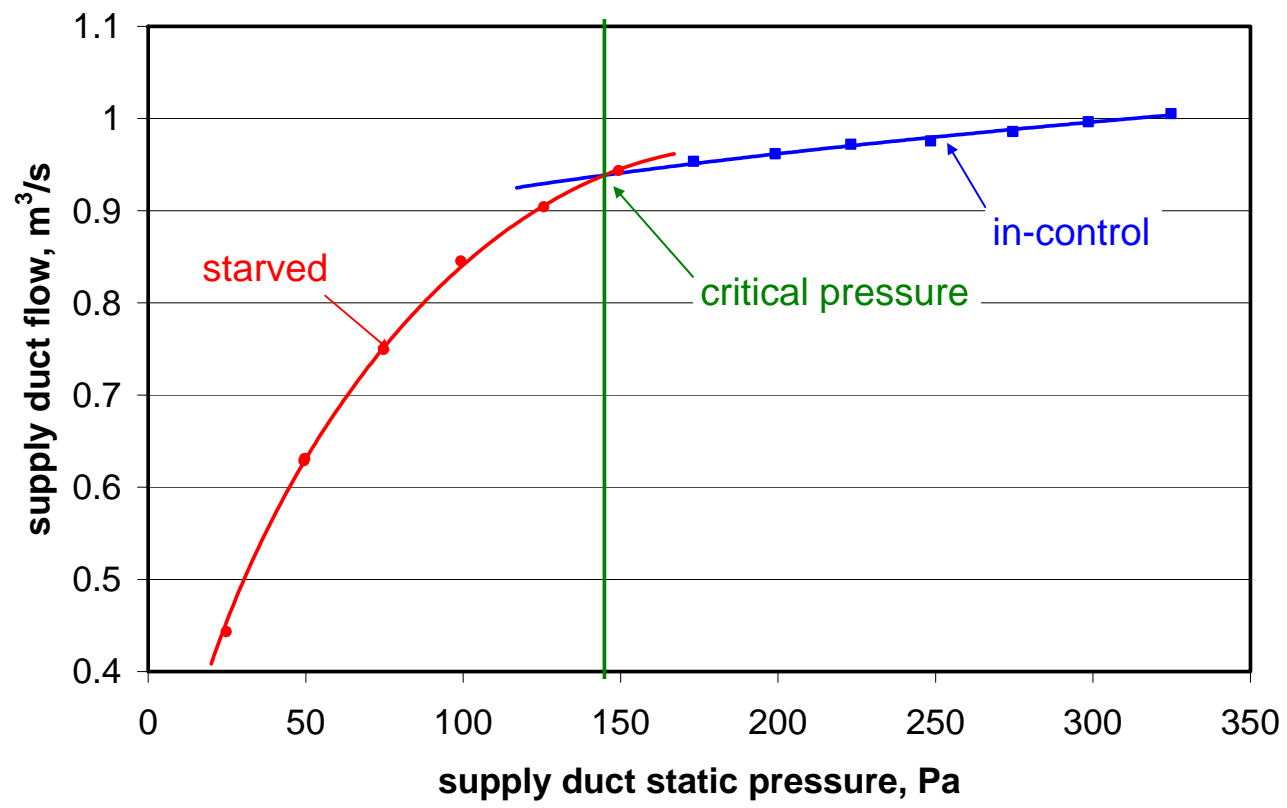

FIGURE 4. Example of SPR Diagnostic Data and Fitted Models

Eq. 2 represents the controlled model for supply flow:

$$
Q_{c}=Q_{0}+C_{p} P^{n}+C_{t} \tau
$$

The first term $\left(Q_{o}\right)$ on the right-hand side of Eq. 2 is a constant that represents the cumulative flow rate through the terminal box dampers in the controlled mode that is independent of pressure and time. Using the cumulative flow is an important advantage because it makes the resulting SPR strategy more robust in response to individual terminal box failures. The second term accounts for duct leakage upstream of terminal boxes. $C_{p}$ is a leakage coefficient, $P$ is the duct static pressure, and $n$ is the leak pressure exponent (typically 0.5 ). The third term accounts for the loads and therefore the supply flow changing over the course of the diagnostic test in response to changing zone temperatures. $C_{t}$ is the rate of change of the supply flow due to changing load and $\tau$ is time. 
When the duct static pressure drops below the critical pressure, the flow through the dampers becomes a function of the pressure and Eq. 2 no longer applies. In this starved mode, the supply flow can be modeled using Eq. 3:

$$
Q_{S}=\left(C_{0} P^{n}+C_{1} P^{1+n}+C_{2} P^{2+n}\right)\left(1+\frac{C_{t} \tau}{Q_{0}}\right)+C_{p} P^{n}
$$

Eq. 3 has three additional parameters: the polynomial coefficients $C_{0}, C_{1}$, and $C_{2}$, which are used to model the flow coefficient as a quadratic function of pressure. The term $C_{t} \tau / Q_{o}$ compensates for the fact that only a fraction of the terminal flows (those of unstarved terminals) may be changing with time in response to changing loads.

To determine the various coefficients for each model and then the critical pressure, the following least squares analysis procedure can be applied to the diagnostic data:

2.1. Assign the first $\mathrm{N}$ high-pressure points at the beginning of the test (from Step 1.2) and the M low-pressure points at the end of the test (from Step 1.3) to the controlled model. Estimate the coefficients in Eq. 2 using least squares. Determine if the time-dependent term can be dropped from the model using a t-test with a decision probability of 0.02 .

2.2. Assign the remaining data points to the starved model (Eq. 3). Estimate the three polynomial coefficients of the starved model using the coefficients determined from the controlled model (Step 2.1).

2.3. Compute the variance of the combined residuals.

2.4. Repeat steps 2.1 through 2.3 for all allowable values of $\mathrm{N}$ and $\mathrm{M}$, and choose the values of $\mathrm{N}$ and $\mathrm{M}$ that produce the lowest variance.

2.5. Determine the pressure at which the flow predicted by the starved model (Eq. 3) equals the flow predicted by the controlled model (Eq. 2).

For the data shown in Figure 4, the critical pressure determined using this procedure is $145 \mathrm{~Pa}$. Substantial fan energy savings are possible by implementing SPR for this system, compared to simply operating at the design pressure of about $325 \mathrm{~Pa}$. Specific savings will depend on the pre-control design flow and static pressure, the temporal load distribution, and the efficiency of the fan, motor, and drive.

Future efforts should focus on simulations and field experiments to assess the range of savings that can be achieved using this technique in comparison to the savings associated with conventionally configured ad hoc reset strategies and common zonelevel DDC-based strategies.

\section{EFFICACY OF INTERMITTENT VENTILATION}

Ventilation is principally used to maintain acceptable indoor air quality (IAQ) by controlling indoor contaminant concentrations. A key step in designing a ventilation system is determining the correct amount of ventilation and the optimal system with which to provide it. There is no shortage of guidance on how much ventilation to use and codes and standards typically require constant ventilation. There are, however, a variety of reasons why the ventilation should not always be constant. For example:

- There may be periods of the day when the outdoor air quality is poor and one wishes to reduce the amount of outdoor air entering the building; 
- Economizer operation can excessively ventilate a space from the point of view of indoor air quality; energy savings can be achieved by using lower ventilation rates at other times that take into account the excess ventilation;

- Demand charges or utility peak loads may make it advantageous to reduce ventilation for certain periods of the day; and

- Some HVAC equipment, such as residential or small commercial systems that link ventilation to heating and cooling system operation, may make cyclic operation more attractive than steady-state operation.

If ventilation rate and contaminant concentration were linearly related, the average concentration would be proportional to the arithmetic average ventilation and straightforward methods could be used to determine the effectiveness of intermittent ventilation. Unfortunately, ventilation and concentration are dynamically and inversely related through the mass continuity equation, which leads to a typically nonlinear relationship between ventilation and concentration.

Sherman and Wilson ${ }^{12}$ and Yuill ${ }^{13,14}$ solved the continuity equation for the general case and defined temporal ventilation effectiveness (i.e., efficacy), $\varepsilon$, as a measure of how good a time-varying ventilation pattern is at providing acceptable IAQ. In particular, the efficacy is the ratio of the required constant ventilation rate to the actual ventilation rate; it links the equivalent (or desired) steady-state ventilation air-change rate $\left(A_{\text {eq }}\right)$, the actual rates of over-ventilation and under-ventilation air-change rates ( $A_{\text {high }}$ and $\left.A_{\text {low }}\right)$, and the fraction of time that the space is under-ventilated $\left(f_{\text {low }}\right)$ :

$$
\varepsilon=\frac{A_{\text {eq }}}{f_{\text {low }} A_{\text {low }}+\left(1-f_{\text {low }}\right) A_{\text {high }}}
$$

If one has an independent measure of the efficacy, it can be used with Eq. 4 to determine the range of acceptable design parameters. When such a measure is unavailable, a dimensionless closed-form expression can be used to determine the efficacy:

$$
\varepsilon=\frac{1-f_{\text {low }}^{2} \mathrm{~N} \cdot \operatorname{coth}(\mathrm{N} / \varepsilon)}{1-f_{\text {low }}^{2}}
$$

where the nominal turn-over $(\mathrm{N})$ in Eq. 5 is defined as:

$$
\mathrm{N} \equiv \frac{\left(A_{e q}-A_{\text {low }}\right) \cdot T_{\text {cycle }}}{2}
$$

$T_{\text {cycle }}$ in Eq. 6 is the ventilation strategy cycle time (i.e., the combined period of a repeating high and low ventilation pair), which typically has units of hours. Figure 5 displays the relationship between the dimensionless parameters in Eq. 5 .

The nominal turn-over is dimensionless, but we can use Eq. 6 to define a critical time, which is twice the equilibrium turn-over time (or 2 divided by the net equilibrium air change rate):

$$
\tau_{\text {critical }} \equiv 2 /\left(A_{\text {eq }}-A_{\text {low }}\right)
$$

Variations in ventilation that happen in cycle times that are short compared to this critical time are effectively averaged out, but cycles that are longer than the critical time may be quite inefficient. 


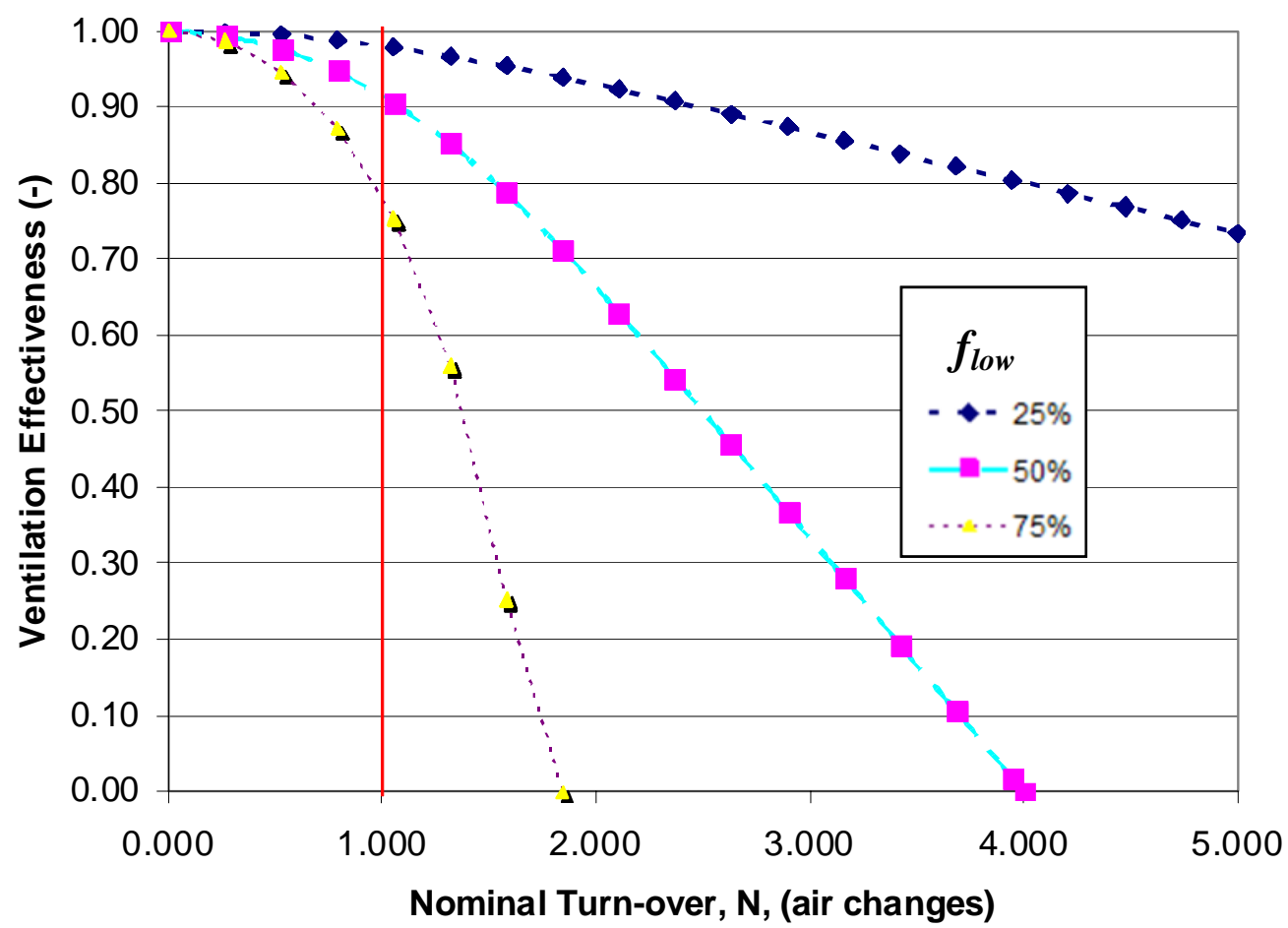

FIGURE 5. Efficacy as a Function of Nominal Turn-Over and Under-Ventilation Time Fractions

When the nominal turn-over is much less than unity $(\mathrm{N}<<1)$, the cycle time is short compared to the critical time and the efficacy is always high (close to unity). Almost any pattern of ventilation will work temporally efficiently. The efficacy approaches unity approximately linearly as can be seen by taking that limit of Eq. 5:

$$
\varepsilon \square 1-f_{\text {low }}^{2} \mathrm{~N}^{2}
$$

For higher nominal turn-over $(\mathrm{N}>>1)$, the cycle time is long compared to the critical time and the effectiveness depends strongly on the fraction of time that the space is under-ventilated. Eq. 5 can be approximated in this regime as follows:

$$
\varepsilon \square \frac{1-f_{\text {low }}^{2} \mathrm{~N}}{1-f_{\text {low }}^{2}}
$$

In the latter case, especially for the large under-ventilation fractions (e.g., 75\%), the effectiveness drops to zero at some point and certain combinations are simply not possible. That is, one cannot always find an on-cycle air change rate that can be used intermittently to provide ventilation equivalent to the continuous ventilation case.

When there is significant under ventilation, neither of these approximate expressions works very well in the critical regime near $\mathrm{N}=1$.

As an example application of these principles, consider the case where one wants to be able to shut down the ventilation system for a period of time during the day to coast through some period of high cost or high outdoor pollution (called notch ventilation). Figure 6 plots the fractional increase in ventilation equipment capacity that is necessary to accommodate a notch of various sizes. The calculations were carried out using Eq. 5 and 6 for two air change rates $(0.5$ ach and 1.0 ach) for the case where 
there was no infiltration during the off period and the case where there was 0.2 ach of infiltration during the off period.

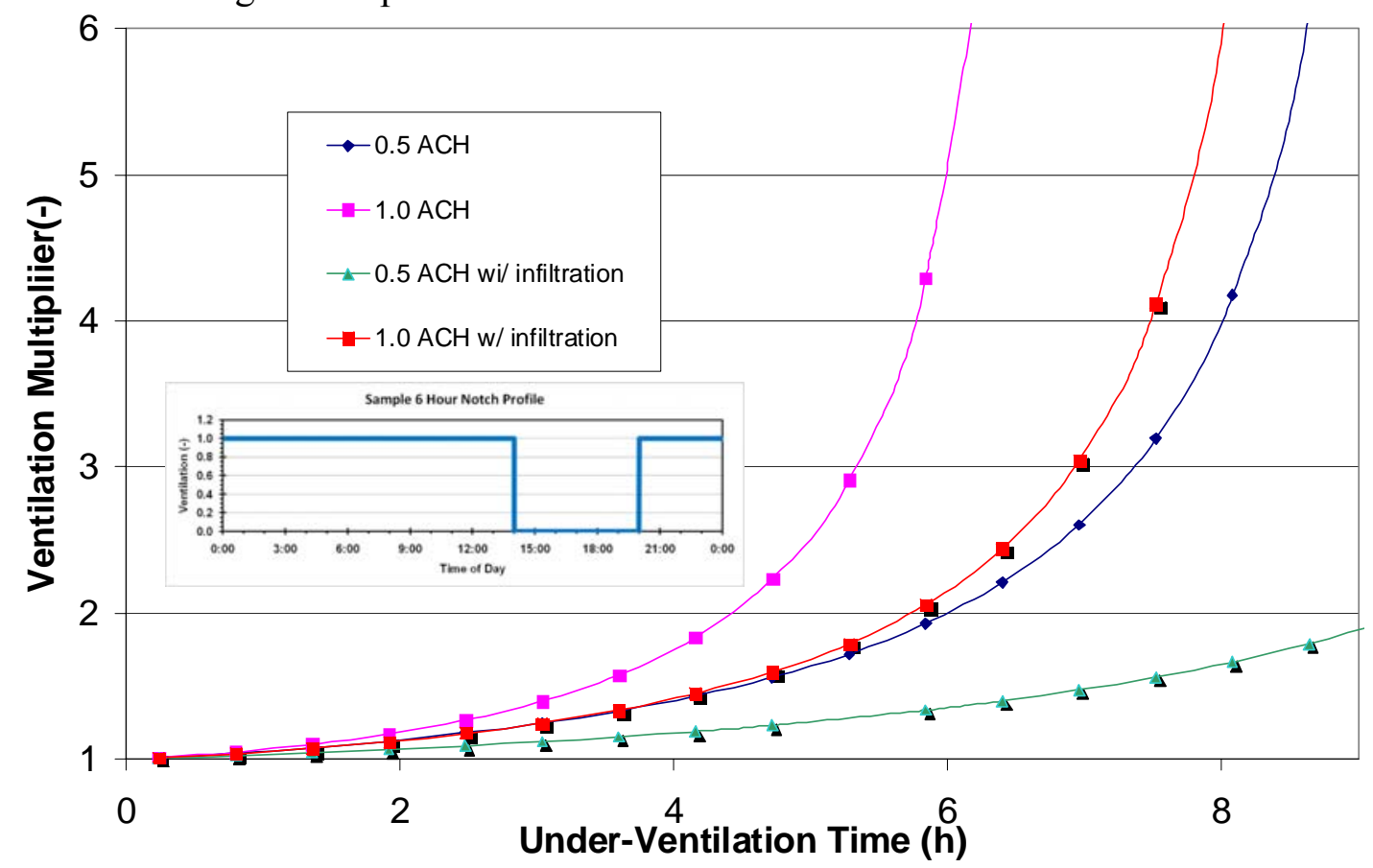

FIGURE 6. Fractional Increase in Ventilation Capacity Needed for an Under-Ventilation (Notch) Strategy, with and without 0.2 ach of Infiltration

If the objective is to achieve a substantial period with the ventilation system off (e.g., at least 6 hours per day) and not to radically increase the size of the ventilation system (e.g., ventilation multiplier of 2), then the ventilation requirement of the space should not be more than about 0.5 ach. For low-density spaces (e.g., offices and large homes), one can achieve this goal; for high density spaces (e.g., conference rooms and theaters), one may not.

Figure 6 also shows that the presence of infiltration during the notch when the ventilation system is off can be quite helpful. For example, if the ventilation requirement is 0.5 ach and there is 0.2 ach of infiltration when the ventilation system is off, one can have a notch that is almost 8 hours per day for only about a $50 \%$ increase in ventilation system capacity.

Future efforts should focus on non-steady-state and/or multilevel modeling and experimental verification, as well as specific application development.

\section{SUMMARY}

We have illustrated three novel diagnostic and control technologies that allow one to improve the performance of air-handling systems: one assesses duct leakage, the second configures an ad hoc duct-static-pressure reset strategy, and the third determines what intermittent ventilation strategy is equivalent to a constant ventilation strategy. 
The DeltaQ duct leakage test described in this paper has been developed over the past several years as an alternative to duct pressurization testing. With the addition of the new ramping technique for obtaining measured data, resolution has been increased at low envelope pressures and the test is quicker and easier to perform. Future efforts should focus on field testing this diagnostic in more houses to confirm preliminary findings that repeatability is affected more by envelope leakage than by wind-induced pressure fluctuations, and to extend its applicability to small commercial buildings.

The standard way to reset supply duct static pressure duct pressure is to control the most-open terminal damper to a nearly open position. Most systems can't measure terminal damper positions or do not have DDC capabilities, so the pressure is either not reset or suboptimal ad hoc reset strategies are used. The short, simple functional test and data processing technique described in this paper can, however, be used to configure these systems to improve their performance. Future efforts should focus on simulations and field experiments to assess the savings that can be achieved using this technique in comparison to the savings associated with conventional ad hoc reset strategies and common zone-level DDC-based strategies.

Ventilation standards and guidelines rarely address intermittent ventilation, so it is not always clear when one is allowed to average out variable ventilation rates and over what period of time one can do this. The model described in this paper can be used directly to address these issues. For example, there is a critical time for averaging the effects of intermittent ventilation. Any variations that happen faster than that critical time are essentially averaged out; things that happen slower than that critical time do not get averaged out and can lead to poor performance, which means increased costs to provide acceptable ventilation. Future efforts should focus on non-steady-state and/or multilevel modeling and experimental verification, as well as specific application development.

\section{ACKNOWLEDGMENTS}

This work summarized in this paper was supported by the Assistant Secretary for Energy Efficiency and Renewable Energy, Office of the Building Technologies Program, U.S. Department of Energy under Contract No. DE-AC02-05CH11231; by the California Institute for Energy Efficiency (CIEE), which is a research unit of the University of California; and by the Energy Innovations Small Grants (EISG) Program, which is part of the California Energy Commission's Public Interest Energy Research Program.

\section{REFERENCES}

1. I.S. Walker, D.J. Dickerhoff, and M.H. Sherman, "The DeltaQ Method of Testing the Air Leakage of Ducts", ACEEE Summer Study Proceedings, Washington, D.C.: American Council for an Energy Efficient Economy, LBNL 49749, 2002.

2. I.S. Walker and D.J. Dickerhoff, "Field and Laboratory Evaluation of a New Ramping Technique for Duct Leakage Testing”, Berkeley, CA: Lawrence Berkeley National Laboratory Report LBNL-62262, 2007.

3. C.C. Federspiel, "Energy-Efficient Air-Handling Controls," Sacramento, CA: California Energy Commission Publication P500-03-052F, 2003.

4. C.C. Federspiel, "Detecting Critical Supply Duct Pressure”, ASHRAE Transactions, Vol. 111, Part 1, 2005. 
5. M.H. Sherman, "Efficacy of Intermittent Ventilation for Providing Acceptable Indoor Air Quality". Berkeley, CA: Lawrence Berkeley National Laboratory Report LBNL-56292, 2004.

6. C.P. Wray, R.C. Diamond, and M.H. Sherman, "Rationale for Measuring Duct Leakage Flows in Large Commercial Buildings", Proceedings - 26th AIVC Conference, Brussels, Belgium, LBNL-58252, September 2005.

7. D.J. Dickerhoff, I.S. Walker, and M.H. Sherman, "Validating and Improving the DeltaQ Duct Leakage Test", ASHRAE Transactions, Vol. 110, Part. 2, LBNL 53959, 2004.

8. I.S. Walker, M.H. Sherman, and D.J. Dickerhoff, "Reducing Uncertainty for the DeltaQ Duct Leakage Test", Proceedings - ASHRAE/DOE/BTECC Thermal Performance of the Exterior Envelopes of Buildings IX, LBNL53549, 2004.

9. I. Walker, M. Sherman, J. Siegel, D. Wang, C. Buchanan, and M. Modera, "Leakage Diagnostics, Sealant Longevity, Sizing and Technology Transfer in Residential Thermal Distribution Systems, Part II", CIEE Residential Thermal Distribution Systems Phase VI Final Report, Berkeley, CA: Lawrence Berkeley National Laboratory Report LBNL 42691, December 1998.

10. J. Siegel, J. McWilliams, and I. Walker, "Comparison Between Predicted Duct Effectiveness from Proposed ASHRAE Standard 152P and Measured Field Data for Residential Forced Air Cooling Systems", Berkeley, CA: Lawrence Berkeley National Laboratory Report LBNL-50008, 2002.

11. D.M. Lorenzetti and L. K. Norford, "Pressure Setpoint Control of Adjustable Speed Fans", Journal of Solar Energy Engineering, 116, 1994.

12. M.H. Sherman and D.J. Wilson, "Relating Actual and Effective Ventilation in Determining Indoor Air Quality", Building and Environment 21 (3/4), 1986.

13. G.K. Yuill, "The Variation of the Effective Natural Ventilation Rate with Weather Conditions", Proceedings Renewable Energy Conference '86. Solar Energy Society of Canada Inc., 1986.

14. G.K. Yuill, "The Development of a Method of Determining Air Change Rates in Detached Dwellings for Assessing Indoor Air Quality”, ASHRAE Transactions, Vol. 97, Part 2, 1991. 